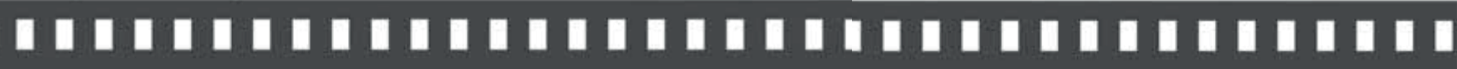

\section{Fotojornalismo: o real e o verosímil}

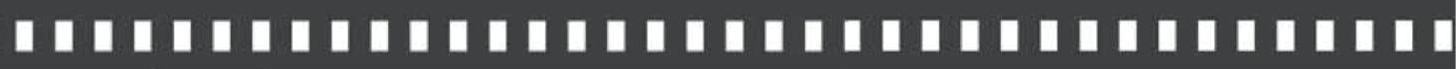

Fátima Lopes Cardoso

Artigo recebido em: 22/09/2017

Artigo aprovado em: 18/06/2018 


\title{
Fotojornalismo: 0 real e o verosímil
}

\author{
Photojournalism: the real and the plausible
}

Fátima Lopes Cardoso*

Resumo: Este artigo nasce da investigação "A Fotografia Documental na Imprensa Nacional: o Real e o Verosímil”, um estudo desenvolvido em 2014, na Universidade Nova de Lisboa-FCSH (Faculdade de Ciência Sociais e Humanas), que pretendeu perceber a essência da fotografia de imprensa portuguesa através das representações que os fotógrafos traçam da fotografia, do ato fotográfico e do jornalismo. Num universo português de pouco mais de 200 profissionais exclusivamente de informação generalista, com uma amostra de 90 entrevistas, concluiu-se que a fotografia de imprensa é a perspectiva do fotógrafo sobre o real e aproxima-se muito mais da verossimilhança do que do real.

Palavras-Chave: Fotografia. Fotojornalismo. Real. Verosímil. Memória. Natureza mnemónica da fotografia. Ato fotográfico.

Abstract: This article is born from The Documental Photography in the Portuguese Press: the Real and the Plausible, a research developed in 2014, at Universidade Nova de Lisboa-FCSH (NOVA School of Social Sciences and Humanities), that intended to perceive the essence of the Portuguese press photography through the representations that photographers draw from photography, photography act and journalism. In a universe of just over 200 Portuguese professionals exclusively of general information, with a sample of 90 interviews, it was concluded that press photography is the photographer's perspective on the real and it is much closer to plausible than to reality.

Keywords: Photography. Photojournalism. Real. Plausible. Memory. Mnemonic nature of photography. Photographic act.

* Doutora em Ciências da Comunicação, especialidade Comunicação e Artes, na FCSH, da Universidade Nova de Lisboa. Professora, na Universidade Autónoma de Lisboa e Escola Superior de Comunicação Social de Lisboa. E-mail: fatimalcardoso@gmail.com 


\section{A Função Testemunhal e Mnemónica da Fotografia}

A ideia de que a fotografia é um processo maquínico que regista o real parece legitimar, ainda hoje, o ato fotográfico na imprensa. Apesar de a maior parte dos fotojornalistas ou fotógrafos documentais assumir a perspetiva pessoal e com as suas escolhas selecionar um fragmento da realidade nas práticas editoriais, ainda se recorre ao pretexto da objetividade jornalística para utilizar a imagem enquanto força maior que comprova o que nenhuma palavra pode demonstrar.

Confiante na natureza técnica que está na gênese da imagem fotográfica, resultado de um processo mecânico e da simbiose entre a física e a química, o observador da fotografia de imprensa, agora adaptado ao eletrônico, ancora referências num mundo visual que lhe é mostrado sempre que olha para os jornais em papel ou online. Se a fotografia mostra, é porque é verdade. Esta crença incontestável na fotografia documentalista publicada em imprensa funciona como única ponte de acesso a realidades que não se conseguem testemunhar. As palavras oferecem-lhe o relato dos acontecimentos, descrevem os pormenores, mas, para o leitor, só as provas visuais são inteiramente alheias aos desvios da imaginação e, portanto, merecedoras de confiança.

Acontece no campo do jornalismo, mas também na necessidade de consolidação da memória individual e coletiva. Quando a atriz francesa Marion Cottillard, no filme de Nicole Garcia, Males des Pierres - título adaptado em português para 
Um Instante de Amor (2016) -, corre a abrir uma mala onde tinha guardado a única fotografia que lhe poderia garantir que a relação que viveu realmente existiu, o que a protagonista procura, desesperadamente, é uma prova de que tudo o que tinha vivido não passou de alucinação. Se a fotografia não mostra, é porque não é verdade.

Esta consciência de que a fotografia deixa provas de uma existência perdida parece ter instigado Roland Barthes, ao observar a fotografia da sua mãe, a escrever A Câmara Clara, hoje uma das reflexões mais preciosas sobre a natureza da fotografia. Como escreve nas páginas introdutórias: “Aquilo que a Fotografia reproduz até ao infinito só aconteceu uma vez: ela repete mecanicamente o que nunca mais poderá repetir-se existencialmente" (BARTHES, 2001, p. 17).

Desde que surgiu oficialmente, em agosto de 1839, a fotografia passou a provar que aquele momento, pessoa, objeto ou lugar, realmente, estiveram em frente da objetiva. Gerou-se um sentimento de pertença a um mundo comum tornado possível pela invenção de Niépce, Daguerre, Talbot, Gerber, Florence e tantas outras contribuições. Este sentimento foi crescendo e nem mesmo as novas técnicas audiovisuais, como a televisão e o vídeo, que surgiram ao longo do século XX, anularam este atributo da fotografia. Como acredita Régis Debray (2000), para o homem moderno, apenas o visível e o que parece óbvio é merecedor de confiança, embora a verdade da imagem esteja escondida na invisibilidade, nos «códigos invisíveis do visível». É no que não é óbvio ao olhar que se revela a essência da imagem. $\mathrm{O}$ que o observador vê e identifica na fotografia não é mais do que um conjunto de valores e 
de experiências partilhadas. Daí a necessidade, exaltada por Walter Benjamin, de atribuir mais importância à funcionalidade social da fotografia como arte para perceber a sua natureza, reconhecendo que as discussões sobre a validade artística da fotografia foram, quase sempre, estéreis para conhecer a sua ontologia (BENJAMIN, 2006, p. 257).

Primeiro com a criação da Kodak e depois com o digital, em diferentes escalas e dimensões, a juntar à facilidade de acesso ao distante trazida pela Internet, a capacidade de fotografar o mundo deixou de ser um saber exclusivo das elites e de profissionais, um pouco como aconteceu com todas as manifestações artísticas, embora com a ressalva que a fotografia é, na sua origem, um dispositivo nascido na era do reproduzível e que tem a condição de cópia na sua natureza.

A facilidade com que se clica hoje num botão para registar uma viagem, um momento fugaz ou obter um retrato familiar confere à fotografia uma sombra de banalidade, desapropriando aparentemente os fotógrafos profissionais de saberes que outrora eram exclusivos, ao mesmo tempo que se perde a noção da sua importância enquanto linguagem universal. Todos queremos visualizar e eternizar as nossas experiências para além da imagem mental e a fotografia satisfaz o ensejo de apropriação de lugares, objetos e de um mundo de afetos que tememos perder, mas que um fotograma paralisa, como se fosse o eterno reencontro com o tempo perdido. Na privacidade, usa-se a fotografia para contrariar a inevitável passagem do tempo e nos lembrarmos das experiências vividas, para tornar mais terna a certeza que todas aquelas situações se irão dissipar, mas que um dia realmente existiram. Só conhecemos 
o rosto dos nossos antepassados ou como eram os seus traços na juventude porque um processo alquimista resgatou do tempo dos mortais a imagem de alguém refletida graças à luz, atirando-a para um tempo infinito. Quer seja no espaço público como privado, a fotografia é como um espelho do momento condenado a desaparecer.

Pactuando com a tese de Bourdieu sobre a necessidade de registar todos os momentos de família, Rosalind Krauss considera que «a máquina fotográfica é vista como uma ferramenta que não tem outra utilidade senão ilustrar, registar passivamente o facto objetivo da integração do grupo familiar» (KRAUSS, 2010, p. 221). É como se o ser humano sentisse necessidade de gerar simbolismo em cada momento da sua vida para valorizar a sua existência e criar um significado no mundo. «...A sociedade tem necessidade de definir as coisas como sendo reais; isto leva-a a insistir no realismo e na total objetividade do testemunho produzido (KRAUSS, 2010, p. 221).

Entre o simples clique da câmara, que muitos teóricos explicam pelo desejo de registo de uma experiência individual (Sontag, Freund, Fontcuberta, Bourdieu, Krauss, Mitchell), e o ato fotográfico profissional existem distâncias consideráveis que é preciso aferir para perceber o valor da fotografia. Se a encararmos como um bem imaterial e necessário para uma sociedade informada, no caso do fotojornalismo, ou a fotografia enquanto valor, se a entendermos numa perspetiva de bem de consumo, um dos enigmas da mudança de paradigma dos media, ainda em metamorfose. Enquanto para o homem comum a fotografia surge da necessidade de materializar um momento efémero, o profissional assume-se como um mensageiro de uma realidade que reporta para um espaço 
público. As diferentes intencionalidades e objetivos fotográficos levam a que os registos individuais raramente tenham outro valor para além do interesse pessoal:

De facto, o amador que regressa a casa com uma série de fotografias artísticas não nos satisfaz mais do que um caçador que volta da sua batida com muitas peças de caça que só têm interesse para o comerciante. E na verdade não tardará muito a chegar o dia em que haverá mais revistas ilustradas do que lojas onde se vendem caça e aves. Isto, no que se refere ao hábito de "bater umas chapas". Mas a perspectiva muda completamente se passarmos da fotografia como arte para a arte como fotografia (BENJAMIN, 2006, p. 257).

Para apelar aos sentidos e exercer a sua função emotiva, a fotografia também segue, muitas vezes, uma estética do belo, mesmo no registo de situações melindrosas da humanidade. As imagens de guerra de W. Eugene Smith, James Nachtwey ou Sebastião Salgado, entre outros, têm a dimensão estética muito presente. Em grande parte das obras dos três fotojornalistas, há vestígios do mesmo conceito artístico da escultura Pietà, de Michelangelo. Da autoria de W. Eugene Smith, a fotografia Tomoko Uemura in Her Bath ("Tomoko Uemura no Banho") mostra uma mãe a dar banho à sua filha, uma rapariga de catorze anos com profundas deformações físicas causadas por envenenamento por mercúrio, vítima do desastre na baía de Minamata, no Japão, causado pela empresa Chisso. Tal como refere Sontag (2003), em Olhando o Sofrimento dos Outros, o olhar da mãe de Tomoko para com a filha tem o sentido de misericórdia muito presente. A construção estética, que 
vive muito da perfeição das composições com luz, aperfeiçoada na fase de edição, também fortalece a conotação da fome e miséria presente nos retratos de Salgado (1999). O mesmo acontece com a maior parte das imagens de Nachtwey em palcos de conflito que reportou, dos Balcãs, a África, à Ásia ou ao Médio-Oriente.

A universalidade dos códigos da linguagem fotográfica contribui ainda para consolidar a função mnemónica da fotografia. As compreensão das palavras exige conhecimento de um idioma, a imagem desperta estímulos básicos da percepção visual. Em Words and Pictures, o norte-americano Arthur Rothstein descreve, de forma simples, a ausência de limites da fotografia: As imagens fotográficas poderosas são fixadas na memória mais rapidamente do que as palavras, porque o fotográfico não precisa de intérprete. Significa a mesma coisa em todo o mundo» (ROSTHSTEIN, 1956, p. 5).

A fotografia, sendo uma construção da realidade através de fragmentos do real que o fotógrafo se apropria figurativamente, sendo o registo do presente que se torna passado, mas permanece como objeto no futuro, revela-se uma muleta da memória que aviva na consciência existências passadas. $\mathrm{O}$ representar traz à presença da consciência do ente o objeto ou situação. «Re-presentar é objectivação que avança, que doma. O representar empurra tudo para dentro da unidade do que é assim objectivo. O representar é coagitatio..., o que se traduz por 'pensante'...» (ROSTHSTEIN, 1956, p. 133).

A similaridade da imagem refletida com o real dá então impulso ao verosímil; ao que fundamenta na ideia de verdade, sem ser propriamente a verdade em si. A verdade é que a imagem do espelho não é um outro real, mas apenas um reflexo, a duplificação. 
Não obstante, é essa imagem que possibilita o conhecimento do real. E volvidos quase dois séculos sobre as primeiras aproximações ao que hoje se entende por fotografia, na atualidade, reconhecese que a imagem jornalística é uma transformação/reconstrução da realidade, uma vez que o acontecimento visível é reportado pelos "filtros" e pelas impressões do fotógrafo. O que a imagem mostra aconteceu, mas o que chega ao público do acontecimento é um pedaço, um fragmento do real. E inevitável que assim seja. "A história da fotografia pode ser contemplada como um diálogo entre a vontade de nos aproximarmos do real e as dificuldades para o conseguir fazer" (FONTCUBERTA, 2002a, p. 12).

Aideia da mimese herdada dos primórdios do daguerreótipo é abolida com a semiótica, que passa a entender a fotografia como uma linguagem, uma representação de um ser cultural, detentor de valores e crenças. Desde o ato fotográfico até à recepção da imagem, a fotografia assume a função de ícone, índice e símbolo (Peirce), ou seja, a imagem fotográfica não pode ser entendida sem a sua experiência referencial (índice); ela é a uma reprodução mimética do real (ícone), a fotografia é uma interpretação, incorpora um conjunto de códigos culturais e ideológicos, em que a realidade fotografada sofre uma transformação (símbolo). «A imagem fotográfica tornase inseparável da sua experiência referencial, do ato que funda. A sua realidade primeira é uma afirmação da existência. A fotografia é, primeiramente, índice. Somente depois pode tornar-se semelhante (ícone) e adquirir sentido (símbolo) (DUBOIS, 1992, p. 47).

Pensar a fotografia como transformadora do real cresce assente nas teorias da percepção e é defendida por teóricos como Hubert Damisch (1963), Pierre Bourdieu (1965), Jean-Louis 
Baudry (1968) ou Charles Sanders Peirce (1978). A fotografia passa a ser encarada como uma linguagem carregada de significados e fiel a códigos de linguagem, que atribui determinado sentido ao real. Desmistifica-se assim a ideia da fotografia enquanto pura mimese, pois ao produzir sentido, considera não apenas o ato de produção da fotografia, mas também o de recepção, contemplação e interpretação.

A fotografia é um sistema convencional que exprime o espaço segundo as leis da perspetiva (melhor, duma perspetiva) e os volumes e as cores por meio de graduações de preto e branco. Se a fotografia é considerada como um registo perfeitamente realista e objetivo do mundo visível, é porque se lhe associou (desde a origem) usos sociais tidos por 'realistas' e 'objectivos'. E se ela se propôs imediatamente com as aparências de uma 'linguagem natural', é no entanto a selecção que opera no mundo visível, antes de mais, que é conforme na sua lógica com a representação do mundo que se impôs na Europa desde o Quattrocento (BOURDIEU, 1965, p. 108,109).

O ato fotográfico não é um exercício simples da captura da realidade, mas o resultado de um momento de concentração e introspeção, à procura do melhor ângulo de visão para mostrar uma perspetiva interessante sobre o visível, do aproveitamento da luz, das limitações ou potencialidades do aparelho, da distância a que o fotógrafo se encontra do objeto, entre outros elementos de composição e de enquadramento fotográficos, além das rotinas jornalísticas e das distintas linhas editoriais que definem as agendas dos media. Ao contrário do fotógrafo-amador que cada 
vez mais recorre aos automatismos das câmaras para lhe facilitar a fotografia, o profissional utiliza apenas o dispositivo para construir as suas mensagens, sem se deixar condicionar pelas suas limitações e aproveitando ao máximo as suas capacidades. O ato fotográfico é acompanhado pela intenção do fotógrafo sobre o fragmento da realidade capturado. E as melhores fotografias seriam, na perspetiva de Vilém Flusser, as que mais "evidenciam a vitória das intenções do fotógrafo sobre o aparelho: a vitória do homem sobre o aparelho" (FLUSSER, 1998, p. 62).

No texto Retórica da Imagem (BARTHES, 1964), Roland Barthes atribui à fotografia uma linguagem conotativa, ligada às mensagens simbólicas e a toda a informação que a fotografia contém. $\mathrm{O}$ enquadramento da foto, o posicionamento da câmara em picado, fotografando o assunto acima do nível do olhar, dando a noção de inferioridade ou submissão, ou em contrapicado, inclinando a câmara de baixo para cima, criando a percepção de superioridade e grandeza ${ }^{1} .$. Todos estes procedimentos são informações conotativas da fotografia que geralmente revelam a bagagem social e cultural do fotógrafo, o studium de Roland Barthes, em A Câmara Clara. A tudo o que se vê, é evidente e óbvio na fotografia, que contém a mensagem literal, Barthes identifica como sendo a linguagem denotativa, a informação. Em o Óbvio e o Obtuso, o autor identifica ainda um terceiro sentido, não descritível e obtuso, que «tem uma certa emoção» e transcende o simbólico.

Exceto em algumas situações, a imagem de imprensa

1 Serguei Eisenstein foi dos mestres do cinema que mais usou esta técnica para significar as imagens, em filmes como O Couraçado Potemkin (1925), Alexandre Nevsky (1938) ou Ivan, o Terrivel I e II (1944 - 1958). 
assenta numa ideia de verossimilhança, sem ser necessariamente "mentirosa". Em várias das suas obras, Joan Fontcuberta lança uma visão crítica sobre este meio visual, desconstrói a ideia de que é uma tecnologia ao serviço da verdade e expõe os diferentes momentos em que a fotografia assume a forma enganadora, quer seja enquanto documento jornalístico ou artístico.

Toda a fotografia é uma ficção que se apresenta como verdadeira. Contra o que nos incutiram, contra o que costumamos pensar, a fotografia mente sempre, mente por instinto, mente porque a sua natureza não lhe permite fazer outra coisa. Mas o importante não é se essa mentira é inevitável. O importante é como a usa o fotógrafo, que intenções serve. O importante, em suma, é o controlo exercido pelo fotógrafo para impor uma direção ética à sua mentira. O bom fotógrafo é o que mente bem a verdade (FONTCUBERTA, 2002b, p. 15).

A técnica, as suas possibilidades e limitações servem para o fotógrafo criar o seu ponto de vista e quebrar a indiferença do público perante a imagem. Quando pretende destacar um elemento e isolá-lo do ambiente envolvente recorre a uma teleobjetiva ou grande abertura de diafragma para obter focagens seletivas; em situações em que o importante é as linhas de perspetiva e ponto de fuga, coloca uma grande-angular na máquina ou objetiva de $50 \mathrm{~mm}$. "Fotografar, em suma, constitui uma forma de reinventar o real, de extrair o invisível do espelho e revelá-lo" (FONTCUBERTA, 2002a, p. 45). 


\section{O Real Emoldurado pelo Olhar Pessoal do Fotógrafo}

A história da fotografia dos últimos 60 anos prova que os fotógrafos sempre tiveram a preocupação de se envolver em causas e de utilizar a imagem para denunciar situações sociais injustas. A orientação de muitas reportagens e as fotografias de denúncia são quase uma militância para os profissionais de imprensa. Sem se desviar dos princípios da procura da verdade, as imagens que preenchiam as páginas das revistas Life assumiam claramente a perspetiva e o ponto de vista único, negando-se a ser meros registos fotográficos do real, linha seguida pelos jornais de referência portugueses, nos anos 1990, em alguns suplementos, nas revistas de domingo e nos portfolios publicados. Acredita-se que os jornais que verdadeiramente valorizam a fotografia como um elemento essencial da informação jornalística exijam que os seus fotógrafos tragam para as suas páginas um olhar singular sobre as notícias, uma imagem informativa e não apenas ilustrativa.

Realidades distantes tornam-se próximas das pessoas através dos registos fotográficos de profissionais que arriscaram a vida para serem testemunhas do seu tempo. A liberdade autoral e o reconhecimento da fotografia nas rotinas jornalísticas conquistadas nas décadas de 80 e 90 do século passado, em Portugal, e que são condições defendidas hoje pelos fotógrafos de imprensa são a herança de um passado que tem nas agências de autor as principais referências profissionais. Conscientes do poder da imagem estática, a partir dos anos 1950, os fotógrafos ao serviço da Magnum Photos 
e da Associated Press entenderam que, mais do que o texto, a fotografia precisava de assumir a missão mais nobre do jornalismo: revelar a informação que conduz à verdade; os factos ocultos, o que é desagradável às instâncias de poder e à própria sociedade.

Conjugando as capacidades artísticas com as jornalísticas, misturando a objetividade da imagem com a subjetividade do ato fotográfico, atribui-se a algumas fotografias a influência sobre o rumo dos acontecimentos históricos ${ }^{2}$. Respeitados por uns e considerados "predadores" por outros, se os fotojornalistas não estivessem presentes em momentos chave da História, muitos acontecimentos teriam caído no esquecimento ou não lhe teria sido conferido o impacto obtido no espaço público.

Em Portugal, também existem inúmeros exemplos em que a fotografia documental imortalizou visualmente a História. Em 1972, as fotografias de Eduardo Gageiro eternizaram os atentados nos Jogos Olímpicos de Munique, onde um grupo de terroristas palestinianos, que se apresentou como Setembro Negro, matou onze atletas israelitas. A alegria estampada no rosto de centenas de civis e de soldados ostentando cravos vermelhos no cano da espingarda, a 25 de Abril de 1974, foi captada pelas câmaras de Alfredo Cunha, Carlos Gil, Carlos Granja, Eduardo Gageiro, José Luís Madeira, Varela Gomes, José Antunes e de outros fotógrafos portugueses, que agora se misturavam com os repórteres televisivos no maior acontecimento mediático nacional vivido até ao presente.

2 A Menina com Napalm, do fotógrafo da Associated Press Nick Ut, é o símbolo máximo do horror da guerra. Sem estudos científicos que o comprovem, a esta e outras imagens chocantes é, no entanto, atribuída extrema influência na mudança de opinião pública norte-americana, que levou a manifestações nas ruas e ao fim da Guerra do Vietname. 
A miséria deixada nos anos 1990 pela guerra civil de Angola, no Ruanda, na Guiné, no Iraque, Afeganistão, Bósnia, Etiópia e Eritreia, entre outros palcos de conflito, também foi denunciada pelas objetivas de inúmeros fotógrafos lusos. Todos os verões, imagens publicadas nos jornais mostram o cenário desolador dos incêndios que invadem o País nesta altura do ano, exaltando a expressão de pânico dos populares a quem as chamas ameaçaram destruir as casas, em todos os verões quentes.

As cenas recolhidas por Max Stahl, no cemitério de Santa Cruz, a 12 de novembro de 1991 ao serviço da Yorshire Television, são um exemplo de quanto a imagem é importante para despertar consciências. Se o jornalista inglês não tivesse filmado o massacre de centenas de timorenses, sobretudo estudantes que se manifestavam pela independência, não haveria provas do terror e da tortura dos militares indonésios ao povo de Timor Lorosae ${ }^{3}$. Possivelmente, o mundo não se teria manifestado em favor da independência e o país continuaria sob o jugo indonésio até à atualidade. Apesar de a imagem-vídeo e a imagem televisiva comportarem, pela aproximação em tempo real aos acontecimentos, uma maior capacidade de mobilização, a verdade é que a base da sua linguagem será sempre a fotografia. De tal forma próxima que existe hoje o risco de o futuro da fotografia de imprensa ser, precisamente, um frame extraído de um vídeo.

3 O massacre aconteceu depois de uma missa de homenagem a Sebastião Gomes, um jovem pró-independência assassinado dias antes pelas tropas indonésias. Após a eucaristia, os participantes, a maior parte estudantes, dirigiram-se para a campa de Sebastião Gomes, no cemitério de santa Cruz, em Dilí. Durante as manifestações pela defesa dos direitos dos timorenses e pela independência, as tropas indonésias carregaram sobre os jovens, provocando 271 mortos, 278 feridos e 270 desaparecidos. Além de Max Stahl, também se encontravam no local o fotojornalista britânico Steve Cox e os jornalistas norte-americanos Alain Nairn e Amy Goodman, que acabaram feridos. 
A fotografia constitui o ponto de partida dos mass media que desempenham hoje um papel todopoderoso como meios de comunicação. Sem ela não teria havido nem o cinema nem a televisão. Olhar diariamente para o pequeno ecrã tornou-se uma droga sem a qual milhões de pessoas, hoje, já não podem passar. O inventor da fotografia, Nicéphore Niépce, fez esforços desesperados para fazer valer a sua ideia...para apenas sofrer derrotas e vir a morrer na miséria. Hoje bem poucas pessoas conhecem o seu nome, mas a fotografia, que ele foi o primeiro a realizar, tornou-se a linguagem mais corrente da nossa civilização (FREUND, 1974, p. 202).

\section{Considerações Finais}

Nas respostas dos entrevistados que participaram no estudo, percebe-se que, pela própria natureza da fotografia, os jornalistas de imagem se libertaram mais do discurso da neutralidade do que os redatores, em parte apoiados pela aparente objetividade da imagem e invisibilidade do seu autor. Paradoxalmente, a observação empírica das imagens publicadas prova que é permitida aos elementos icónicos o que é proibido à escrita, por se acreditar que a fotografia não mente, mas as palavras sim. As edições diárias da imprensa estão repletas de exemplos em que o sentido conotativo da imagem revela a informação que é vedada ao texto graças à denotação visual.

$\mathrm{Da}$ totalidade de fotojornalistas, fotodocumentalistas e editores de fotografia que aceitaram responder às perguntas, apenas alguns fotógrafos de agência e jornais com características específicas acreditam que a fotografia é a reprodução fiel da 
realidade, em especial no contexto de imprensa. A maioria dos fotojornalistas ao serviço de jornais e revistas admite que a fotografia tenta corresponder a um conjunto de valores-notícia que cada linha editorial privilegia e é sempre uma seleção do fotógrafo, mesmo que procure ser objetivo.

O "fantasma" da objetividade não abandona, no entanto, os jornalistas, que se sentem obrigados a ser fiéis aos factos do acontecimento ou notícia que a imagem assume como uma forma de esclarecer a verdade e de a tornar credível perante o leitor. No entanto, os factos que perseguem são sempre os desvios à norma que refletem os valores sociais instituídos. A fotografia ainda é mesmo vista como o último bastião da verdade no jornalismo com poder para autentificar o texto. Em entrevista, Manuel Almeida, fotojornalista da agência de notícias portuguesa Lusa, lembra que

[...] há uma grande distração em relação à importância que uma imagem verdadeira pode ter. O último baluarte da credibilidade no jornalismo foi a fotografia. Portanto, foi caindo a credibilidade em vários setores, mas a fotografia manteve-se sempre credivel socialmente. E sempre houve manipulações.

A tese dominante entre a classe é a de que, exceto quando a força dos acontecimentos é soberana, a melhor fotografia será sempre aquela que contém a informação da notícia, mas onde está presente o olhar perspicaz e único do seu autor. António Pedro Ferreira, fotógrafo do semanário português Expresso, afirma:

Se tentarmos saber como se vivia numa determinada época, todas as descrições literárias podem ser romanceadas, não são objetivas ou, pelo menos, tão 
objetivas como as imagens que existem. Quando se quiser saber como é que eram as condições de vida dos emigrantes portugueses em França, nos anos 1960 ou 1980, é incomparavelmente mais preciso e descritivo ver uma imagem fotográfica porque ela é absolutamente verdadeira. A arte, o talento do fotógrafo documental está, para além de mostrar, em sugerir aquilo que não é visível. Quando se diz que uma imagem fotográfica é extremamente objetiva, só se não tivesse um enquadramento à volta e fosse limitada no tempo e no espaço. Obviamente que tem sempre uma carga muito grande de subjetividade. No entanto, não se inventou nada mais preciso, evocativo e descritivo que uma imagem fixa.

Acredita-se, piamente, que o fragmento da realidade escolhido pelo fotógrafo não põe em causa a verdade do acontecimento. Em entrevista, Gonçalo Rosa da Silva, editor de fotografia da revista Visão, sublinha a importância do olhar do fotojornalista para atingir a própria verdade:

Objetividade/subjetividade é um tema interessante e que corre todo o jornalismo. Essa objetividade é impossivel de conseguir. Cada fotógrafo tem a sua maneira de ver os factos e o que acontece à sua frente. Não inventa nada. O fotojornalismo deve e tem de perseguir a verdade. Porque isso é o grande património que temos. Agora, a forma como cada um faz essa fotografia é que difere porque há uma série de opções que o fotógrafo assume antes de premir o disparador da máquina e são essas escolhas que tornam a fotografia subjetiva. Se duas pessoas estiverem a fotografar a mesma coisa, uma fotografa de maneira diferente da outra. Subjetividade só no sentido de verdade. O fotojornalista tem de ser verdadeiro. Não pode inventar nada. Tem de trabalhar com o que está à sua frente. A partir daí, há uma subjetividade inerente à maneira de ver do fotógrafo. 
Grande parte dos entrevistados admite que procura a objetividade no ato fotográfico, mas que não pode ser nada mais do que uma honestidade assente na subjetividade. Reinaldo Rodrigues, editor executivo da Global Imagens, afirma:

Tento ser objetivo e acho que toda a gente tenta. Só que a objetividade jornalística vem do fotógrafo. Nós não somos máquinas e tentamos dar o nosso olhar. Essa também é uma vantagem em relação ao cidadão que fotografa. Para mim, é mais valioso transmitir um contexto. Se estiver num jogo de futebol, o importante não é fotografar a cara do jogador que marcou golo, mas mostrar a envolvência, o estádio, se está vazio ou cheio. Tento dar informação. Essa é a diferença da fotografia no jornal.

Um dos decanos do fotojornalismo português, José Carlos Pratas admite a impossibilidade de ser neutro:

É evidente que temos de ser sempre objetivos, mas não somos isentos. O objetivo é trazer para as páginas do jornal imagens do acontecimento tal qual ocorreu da forma mais interessante que eu saiba. Pode ser mais artística ou - como não gosto da palavra - esteticamente apelativa. Quando fotografo uma pessoa que está a olhar para mim com um ar expressivo, o impacto fotográfico é diferente de estar perante uma pessoa com um ar apático. Mas não somos isentos. Não fotografo uma manifestação de extrema-direita com a mesma perspetiva de fotografar uma manifestação de indignados.

Luís Ramos, fotógrafo e ex-editor do Público, reafirma a necessidade de existir o rigor da objetividade mencionado por Tuchman: 
Embora tanto o fotógrafo como o seu editor não sejam meros veículos da tecnologia, mas sim seres humanos com sentimentos e crenças, os atos de captar ou editar uma imagem, apesar de subjetivos, devem-se sempre reger por rigorosos padrões deontológicos, no sentido da procura da objetividade informativa.

A intenção do ato fotográfico só é possível porque o fotógrafo tem consciência de um objeto ou acontecimento do mundo. É como se cada foto, sendo uma construção subjetiva do olhar do fotógrafo, tivesse como fim a objetividade. A origem da fotografia documental é o referente real, mas também é a capacidade do fotógrafo transpor o acontecimento para um frame. Enquadrado na "moldura" que o autor escolheu e contextualizado numa página de um jornal, esse quadro da realidade tornar-se único e diferenciado dos demais. Cada fotografia de uma mesma realidade oferece um novo olhar e não uma imitação redutora do visível. Como acreditam Ricoeur e Foucault, a imagem não é uma cópia, mas algo único que, à sua maneira subjetiva, contribui para o conhecimento da realidade porque cria um novo enunciado.

A crença na imagem fotográfica como espelho do real, apesar de redutora e das alterações na produção e na recepção da fotografia em diferentes épocas, parece necessária para legitimar a própria fotografia no contexto social. Ao olhar para uma fotografia numa página de jornal, o observador não questiona a veracidade do acontecimento representado, pois confia na imagem técnica e no compromisso com a verdade do jornalismo. A presença da subjetividade fotográfica não diminui essa credibilidade, apenas ajuda a cativar o leitor. 
Admitir que a fotografia é o olhar da pessoa que está por trás da câmara, o resultado da sua leitura do mundo ou de uma parte desse mundo e não a manifestação do real parece uma exigência que mostra o respeito que deve ser atribuído à imagem e ao seu autor. A mudança de posicionamento do fotojornalista de hoje em contraponto à teoria do espelho de Baudelaire (1968), no século XIX, são o resultado de metamorfoses sociais, culturais e políticas profundas, que atingiram o clímax com o aparecimento da Internet e com os novos suportes digitais.

Com base em valores profissionais como o rigor objetivo na procura da verdade, o ponto de vista passa a ser imprescindível para satisfazer as exigências de um público saturado da informação descartável da era digital e que precisa de saber mais do que a televisão e a Internet mostram.

A longo prazo, a crença da imagem concretiza-se pela sua verossimilhança com o real, transportando características que lhe são comuns e assumindo um carácter testemunhal com possíveis proporções históricas. A curto prazo, vale pelo poder de dar a conhecer realidades que de outro modo seriam ocultas ao observador.

\section{Referências}

BARTHES, Roland. A câmara clara. Tradução de Vítor Silva. Lisboa: Ed. 70, 2001. (Arte \& Comunicação).

BARTHES, Roland. Le rhétorique de l'image, Communications, Paris, n. 4, 1964.

BAUDELAIRE, Charles. Oeuvres completes-les public moderne et la photographie: Michel Lévy Frères. Paris: 
Libraires Éditeurs, 1968.

BENJAMIN, Walter. Pequena história da fotografia. In:

A modernidade. Tradução de João Barrento. Lisboa: Assírio \& Alvim, 2006.

BOURDIEU Pierre. Un art moyen, essai sur les usages sociaux de la photographie. Paris: Minuit, 1965.

DEBRAY, Régis. Vida y muerte de la imagen-historia de la mirada en occidente. Tradução de Ramón Hervás. Barcelona: Paidós, 2000. (Paidós Comunicación).

DUBOIS, Philippe. O acto fotográfico. Tradução de Edmundo Cordeiro. Lisboa: Veja, 1992. (Comunicação \& Linguagens).

FLUSSER, Vilém. Ensaio sobre a fotografia: para uma filosofia da técnica. Lisboa: Relógio D’Água, 1998.

FONTCUBERTA, Joan. EI beso de Judas, fotografia y verdad. Barcelona: G. Gili, 2002a.

FOUCAULT, Michel. The Archaeology of Knowledge. Tradução de A. M. Sheridan Smith. Londres: Routledge, 2002b.

KRAUSS, Rosalind. O fotográfico. Barcelona: Gustavo Gili, 2010.

ROTHSTEIN, Arthur. Words and pictures. New York: American Photographic Book Publishing, 1956.

SALGADO, Sebastião. Um fotógrafo em abril. Lisboa: Caminho, 1999.

SONTAG, Susan. Olhando o sofrimento dos outros. Lisboa: Gótica, 2003. 